\title{
TERESA DE CEPEDA Y AHUMADA. UNA VIDA DE AMOR Y TRANSGRESIÓN EN UN MUNDO DE VIOLENCIAS ${ }^{1}$
}

\author{
María Teresa Arias Bautista
}

Teresa de Cepeda y Ahumada. Una vida de amor y transgresión en un tiempo de violencias
Resumen: Teresa de Cepeda y Ahumada fue una mujer peculiar y extraordinaria. Su vida y su
obra literaria y fundacional ha hecho correr tinta desde su propio tiempo hasta el presente. Mi
aportación se centra en tres cuestiones sugerentes y ligadas entre sí: el amor con el que amó, ese
sentimiento intenso del ser humano que, partiendo de su propia insuficiencia, necesita y busca el
encuentro y unión con otro ser, según define la RAE y que ella centró en Dios. En la transgresión,
o su capacidad para romper las normas, y, finalmente, en la violencia que la rodeó. Palabras clave: Mujeres, historia, santidad femenina, Santa Teresa, Inquisición, mujeres escritoras.

Teresa de Cepeda y Ahumada. A Life of Love and Transgression in a Time of Violence Abstract: Teresa de Cepeda y Ahumada was a peculiar and extraordinary woman. Her life and her literary and foundational work have run ink from her own time to the present. My contribution focuses on three suggestive questions and bound together: the love with which she loved, that intense feeling of the human being, from her own inadequacy, needs and seeks contact and union with another being, as defined by the RAE, and which she focused on God. In the transgression, or her ability to break rules, and finally, in the violence that surrounded her.

Key words: Women, history, female holiness, Santa Teresa, Inquisition, women writers.

\section{Una vida de amor}

En el hervidero de comienzos del siglo XVI, nació Teresa. Corría el 28 de marzo de 1515. Era una etapa dorada en muchos aspectos y oscura en otros; convulsa y contradictoria, donde convivían estrechamente Dios y el demonio (Santa Teresa 2015: 965). El panorama intelectual bullía de nuevas ideas y los más diversos personajes daban cuerpo a una sociedad dinámica y singular.

La familia de Teresa era de origen judeo-converso y sobre su abuelo había caído el peso inquisitorial por judaizar. Tuvo que desfilar con los reconciliados durante siete viernes por las iglesias de Toledo, vestido con el sambenito. Sin hundirse por tal

\footnotetext{
${ }^{1}$ Fecha de recepción: 08/11/2015.

Fecha de aceptación: 21/12/2015. ${ }^{2}$ Presidenta de la Agrupación Ateneísta de estudios sobre las mujeres "Clara Campoamor", Madrid; $\square$ ogigias@hotmail.com.
} 
vergüenza y con los medios suficientes para enderezar su vida, obtuvo un favorable pleito de hidalguía en Ciudad Real y la ansiada "limpieza de sangre" con la que comenzó una nueva vida en Ávila (Javierre 2015: 60, 61).

Teresa tenía un hermano y una hermana del primer matrimonio de su padre Alonso de Cepeda con Catalina del Peso y Henao, y otras dos hermanas y ocho hermanos del que le unió a su madre, Beatriz Dávila y Ahumada. A todos mostró Teresa un gran amor y resaltó sus cualidades morales y religiosidad, tal vez para ahuyentar el estigma antes señalado.

Mercedes Rivera hace hincapié en el amor que Teresa sentía por su madre (Rivera 2015: 17). Ello es cierto, pero no lo es menos que sentía una especial inclinación por su padre (Santa Teresa 2015: 34) y que él le correspondía, siendo su hija favorita (Santa Teresa 2015: 34,38). La relación afectiva entre ambos resulta conmovedora. La hija condujo al padre por el camino de oración que a su juicio era el único y verdadero para llegar a Dios. Alonso se esforzó cuanto pudo en seguirla (Santa Teresa 2015: 55).

De su madre, a la que perdió a los doce años, dijo que poseía numerosas virtudes, que le enseñó el amor a los libros y que murió cristianamente (Santa Teresa 2015: 34,36). También que la educó como convenía a una jovencita de su época mostrándole que debía evitar comprometer su honra (Santa Teresa 2015: 37).

Tanto su padre como su madre fueron figuras irremplazables en su vida. En uno de sus éxtasis los vio: "Parecíame estar metida en el cielo, y las primeras personas que allá vi fue a mi padre y madre" (Santa Teresa 2015: 207).

De sus palabras se deduce que Teresa fue una niña y adolescente que halló en la vida familiar el amor que la preparó para amar. Cuando se alejó de ella fue a costa de una gran conmoción interior que comparó con la muerte:

Cuando salí de casa de mi padre, no creo será más el sentimiento cuando me muera; porque me parece cada hueso se me apartava por sí, que, como no havía amor de Dios que quitase el amor del padre y los parientes, era todo haciéndome una fuerza 
tan grande que, si el Señor no me ayudara, no bastaran mis consideraciones para ir adelante. (Santa Teresa 2015: 41)

Igual sentimiento mostró cuando cuidó a su padre enfermo: "En este tiempo dio mi padre la enfermedad... pareciéndome se arrancaba mi alma cuando vía acabar su vida, porque le quería mucho". (Santa Teresa 2015: 56,57)

Un gran amor prodigará a sus hermanas y hermanos, sobrinas y sobrinos (Santa Teresa 2015: 960, 982, 1282), a quienes no solo dedicará tiernas palabras, sino que les ayudará a situarse socialmente recurriendo para lograrlo a sus numerosísimas amistades. Son tan abundantes los testimonios sobre el particular que es imposible enumerarlos (Santa Teresa 2015: 889, 928, 954, 965, 987). Lo cierto es que su inclinación familiar fue de tal magnitud que tuvo dificultades para erradicarla: "No sé yo qué es lo que dejamos del mundo las que decimos que todo lo dejamos por Dios, si no nos apartamos de lo principal, que son los parientes... Yo he sido querida mucho de ellos y yo les quería tanto que no les dejava olvidarme..." (Santa Teresa 2015: 275). Incluso llegó a acusarse de no haber sido capaz de liberarse del mundo por lo apegada que se sentía hacia los suyos (Santa Teresa 2015: 171).

$\mathrm{El}$ amor a los otros fue igualmente una constante. Muy joven aún, intentó "rescatar del demonio a un fraile que tenía una amante”. Según su relato causó más efecto en él para que se arrepintiera el afecto que le demostró, que el hablarle de Dios (Santa Teresa 2015: 46, 47).

Amor sintió en extremos hacia su obra fundacional, hacia sus hijos e hijas espirituales (Santa Teresa 2015: 983, 1410). A estas últimas las quería libres, cultas e inteligentes (Santa Teresa 2015: 875) con independencia de su rango, de su ascendencia y de su peculio (Santa Teresa 2015: 924). Por el contrario, rechazaría a quienes no tuviesen talento y virtud (Santa Teresa 2015: 907-908). Su mayor deseo era que alcanzasen la cima espiritual que ella había logrado. Para ello les allanó el camino con su voz, dictados y experiencias: "deshaciéndome estoy, hermanas, por daros a entender esta operación de amor" (Santa Teresa 2015: 529). Les mostró sabiamente que cada una debía 
seguir el camino en función de sus peculiaridades y con la paciencia que requería cada personalidad (Santa Teresa 2015: 737).

Las quería, igualmente, firmes, capaces de amar sin preferencias individuales (Santa Teresa 2015: 254), sin ruindades, sin melindres, sino con la fuerza varonil capaz de trascenderlas genéricamente y otorgarles equivalencia en poder, estimación y potencia con los varones, de tal manera que aquellos se vieran obligados a admirar su esfuerzo y audacia:

¡Oh que bueno y verdadero amor será el de la hermana que pude aprovechar a todas... Mijor amistad será esta que todas las ternuras que se pueden decir, que estas no se usan ni han de usar en esta casa, tal como "mi vida", "mi alma", "mi bien" y otras cosas semejantes... Es muy de mujeres, y no querría yo, hijas mías, lo fuésedes en nada, ni lo pareciésedes, sino varones fuertes; que si ellas hacen lo que es en sí, el Señor las hará tan varoniles, que espanten a los hombres... (Santa Teresa 2015: 270-271)

Con ese deseo de equiparación no rechazaba la condición femenina; todo lo contrario, era su forma de gritarle al mundo que las mujeres eran capaces de proponerse y desarrollar virtudes consideradas impropias o negadas a las mujeres. También de desprenderse de los eternos y atávicos prejuicios genéricos vigentes, defendidos por sus contemporáneos, como fray Luis de León. Para él, como para tantos intelectuales la mujer varonil era la mujer de valor:

Lo que aquí decimos mujer de valor, y pudiéramos decir mujer varonil... Quiere decir virtud de ánimo, y fortaleza de corazón, industria y riquezas, y poder y aventajamiento, $\mathrm{y}$, finalmente, un ser perfecto y cabal en aquellas cosas a quien esta palabra se aplica... Porque como la mujer sea de su natural flaca y deleznable más que ningún otro animal, y de su costumbre e ingenio una cosa quebradiza y melindrosa... (León 1953: 57-58)

El amor de Teresa hacia las descalzas era tierno, compasivo y flexible. Prefería la virtud al rigor (Santa Teresa 2015: 1052) pues abominaba el castigo (Santa Teresa 2015: 
1037), tan apreciado por las personas que pretendían acercarse a Dios a través del sufrimiento corporal. Como mujer que había hecho una introspección profunda y no se había alejado del contacto con el mundo era capaz de entender no solo la debilidad, sino la maldad y generosamente perdonarla (Santa Teresa 2015: 1212-1213).

El espíritu efervescente y pasional de Teresa se asoma entre los renglones de su obra y en especial en sus cartas. Sus salutaciones, despedidas, recomendaciones; su forma envolvente, locuaz, próxima y contagiosa de comunicar rebosa cariño hacia quienes estimaba o quería. Así hizo con las prioras encargadas de sus fundaciones, con sus amigos y amigas, sus bienhechores y confesores, en especial con Jerónimo Gracián. Su estrecha connivencia levantó insanas murmuraciones e infundios (Santa Teresa 2015: 1123), a pesar de la diferencia de edad y del respeto que destilaban las palabras que ambos se cruzaban. A veces, la vehemencia de Teresa, hija de sus momentos de soledad y angustia, la llevaron a recriminarle su falta de afecto y reciprocidad (Santa Teresa 2015: 1235, 1402). Por miedo a desavenencias o chismorreos innecesarios entre las hermanas, Gracián reprendió las efusiones verbales de Teresa para con él. Ella le respondió, ocurrente, que toda alma, por perfecta que fuera necesitaba un desaguadero y que él era el suyo (Cohen 2006: 76).

Los cruzados mensajes entre Teresa y Jerónimo fueron y han sido motivo de malas interpretaciones provenientes de quienes han leído fuera de contexto las palabras de una y otro. Les unía el deseo común de caminar en Dios y sacar a flote la reforma carmelita. De hecho, Gracián declaró que nada hizo de importancia mientras vivió Teresa sin consultarle:

Estuve en Beas muchos días, en los cuales comentábamos todas las cosas de la Orden, así pasadas como presentes, y lo que era menester para prevenir las futuras; y demás desto, de toda la manera de proceder en el espíritu, y cómo se había de sustentar así en frailes como en monjas. Ella me examinó a mí de todo cuanto sabía en esta doctrina así por letras como por experiencia. Me enseñó todo cuanto ella sabía, dándome tantas doctrinas, reglas y consejos, que pudiera escribir un libro muy grande de lo que aquí me enseño... Dióme cuenta de toda su vida y espíritu e intentos. Quedele tan rendido, que desde entonces ninguna cosa hice grave sin su consejo. (Steggink 1987: 107) 
Teresa encontró en Jerónimo a una persona capaz de entenderla y ayudarla dentro de ese mundo misterioso en el que andaba inmersa (Santa Teresa 2015: 1068). Un mundo plagado de incomprensiones como las que le acaecieron con otros confesores, algunos de los cuales habían visto en su misticismo, para su espanto, cosas del demonio (Santa Teresa 2015: 63, 155). Un escenario en el que hubo de lidiar en solitario en demasiadas ocasiones, a pesar de la fuerza espiritual que le imprimía su convencimiento de obrar de acuerdo con los designios de la divinidad. Lucha denodada en el exterior por culminar la reforma y dejar atadas las fundaciones; en lo interior con sus propios dilemas personas, sus dudas, y la ausencia de afectos. Nadie salvo Gracián fue capaz de comprender toda su grandeza y el ansia de libertad con que soñaba para llevar a cabo la misión para la que se creyó predestinada y ante la que encontró numerosas cortapisas por ser mujer.

Gracián recibió, que se hayan conservado, noventa y siete cartas de Teresa. En ellas refleja el conflicto de ser tres en aquella dualidad recíproca: por un lado madre de Gracián por edad y como fundadora de la orden descalza, por otro hija por ser él su guía espiritual y más tarde superior de la Orden y, finalmente, por ser maestra espiritual de un epígono que iniciaba el camino que ella había culminado: "Ella me comunicó su espíritu sin encubrirme nada, y yo a ella de la misma suerte declaré todo mi interior, y allí nos concertamos de ser siempre conformes en todos los negocios, y ella, además del voto de religión, hizo particular voto de obedecerme toda la vida por una particular revelación que tuvo" (Andrés 2004: 658).

En las épocas de mayor dificultad, especialmente aquellas en que se enconaron las rivalidades de los dirigentes y miembros de la orden calzada hacia ella y su obra, le escribirá de forma críptica. Teresa será Ángela, Gracián será Paulo. Un lenguaje excluyente que no debía ser compartido para evitar malas interpretaciones. De hecho pedirá a Gracián que no las leyese en público (Santa Teresa 2015: 1060).

A pesar de todo este amor mundano hacia las personas de su familia, entorno y seguidores incondicionales, con ser profundo y en ocasiones arrebatado, acabará siendo eclipsado por el amor que la ocupó absolutamente hasta desgarrarla física y mentalmente 
(Santa Teresa 2015: 29). Su amor a Dios no tendrá parangón y todo lo demás le sobrará (Santa Teresa 2015: 1074). Ese estado de exclusión de todo lo que no fuese Dios adquirirá gran fuerza en su poesía (Santa Teresa 2015: 616, 654). Poco a poco, hasta llegar a ese punto, irá avanzando en su caminar místico desde que se decidió a iniciarlo. Al principio vivido de forma inexplicable (Santa Teresa 2015: 102), llegará a poder expresarlo con la fuerza necesaria para arrastrar a otras personas a seguir sus huellas (Santa Teresa 2015: $65)$.

Recíprocamente, y según sus revelaciones, Dios la amaba con la fuerza de las tres personas divinas (Santa Teresa 2015: 597). Su desposorio místico la hacía acreedora de cuanto pidiere a quien nada podía ya negarle (Santa Teresa 2015: 607). Su absoluto convencimiento de hallarse en Dios (Santa Teresa 2015: 616) le hará buscar solo la gloria del amado (Santa Teresa 2015: 592). Es más, solo la muerte, capaz de otorgarle la unión definitiva con la divinidad se convirtió en su máxima aspiración que expresó con las famosas frases: "Vivo sin vivir en mi / Y tan alta vida espero / que muero porque no muero" (Santa Teresa 2015: 654).

\section{Una vida de transgresiones}

El mundo de Teresa lo fue de transgresiones en todos los ámbitos de su experiencia: en el de mujer, en el de hija, en el de monja, en el de cristiana... Parece que no le quedó otro remedio pues las reglas patriarcales se oponían a sus deseos, a su compromiso de fe, a la satisfacción de sus proyectos, a su forma de caminar por el mundo y de comunicarse con sus semejantes y con Dios. No olvidemos que las mujeres seguían siendo para el ideario prevalente personas de segunda categoría, imbéciles, indoctas, incapaces... Los escritos de sus contemporáneos así lo avalan. Fray Luis de León, por ejemplo, aseveraba: "la maldad de la mujer es todas las maldades. Vivir con leones y con dragones es más pasadero que hacer vida con la mujer que es malvada" (León 1953: 46). 
Ser mujer era una auténtica barrera. Como todas las mujeres de su época Teresa aprendió desde muy niña que para ser respetada había de contenerse en sus manifestaciones, en su arreglo, en su forma de estar en el mundo, en la demostración de sus afectos... Pero ella no podía sufrir tal presión: la de los ojos de los otros siempre encima para juzgarla, para domesticarla. Eligió alejarse del mundo, ocultarse a la mirada.

El encierro conventual era solo aparente y no supuso para ella sino una liberación, un recinto ajeno al ajetreo donde dejar volar su espíritu inquieto. El claustro no será, a mi juicio, sino el sutil velo que cubrirá una apariencia y que le otorgará lo que más estimaba: la libertad de pensamiento y, más tarde, la libertad de acción por la que suspiraba.

La vida de quietud que le ofreció el monasterio la ayudó al recogimiento interior, a la oración para la aspirada unión con Dios. Alcanzada la meta, y como hiciera mucho antes que ella otra mística, Hildegarda de Bingen, sintió un profundo e incontrolable frenesí por manifestar la palabra de Dios, por crear lugares propios donde realizar la transformación del ser humano y, como aquella, se amparará en los designios divinos para conseguir sus objetivos, buscando las mañas y apoyos necesarios para darles cumplimiento (Santa Teresa 2015: 181-182).

Según Teresa entendía, la libertad de acción, la libertad de movimientos, se la otorgaba Dios. No obstante, buscó el respaldo de sus confesores para evitar ser enjuiciada como rebelde o desobediente. Fue capaz de andar hábilmente en los límites de lo permitido para superar los peligros que la acechaban. El reconocimiento continuo de la autoridad de la Iglesia, es decir, del conjunto de los varones que la conformaban, hizo difícil a sus enemigos juzgarla fuera de la ortodoxia.

Es cierto que el estado religioso en que encontró su lugar tuvo como contrapartida su asexuación, pero ella le proporcionó el medio de sortear las categorías de infravaloración genérica, tema de larga tradición en el cristianismo, como señaló San Ambrosio: "Debe ser llamada mujer la que no cree y sigue aferrada a sus funciones naturales, pero la que crea en Dios y se dedique a su servicio, se convertirá en un hombre perfecto". O San Jerónimo: "En tanto que la mujer está hecha para el nacimiento y los hijos, es diferente al hombre en cuerpo y alma. Pero si desea servir a Cristo en lugar de al 
mundo, entonces dejará de ser mujer y será llamada hombre" (Pedregal 1998: 271). Palabras similares podemos hallar mucho antes, en el evangelio apócrifo de Santo Tomás: “Cuando Pedro sugiere que María salga del grupo porque las mujeres no son dignas de la vida, Jesús responde que él mismo la guiará para hacerla varón a fin de que ella también llegue a ser espíritu. Porque toda mujer que se haga a sí misma varón entrará en el reino de los cielos" (Bernabé 2007: 37). Teresa no renunció a ser mujer (Santa Teresa 2015: 117), sino que defendió la importancia de las mujeres y de sus obras en numerosas ocasiones otorgándoles el valor que se les negaba (Santa Teresa 2015: 896, 741-742).

La virginidad femenina escogida como fórmula de vida no solo rompía con las ataduras del pecado de la carne, con el que se culpabilizaba a las mujeres de la pérdida de la beatitud primigenia, sino que se convertía en matrimonio místico, el mejor que estado que pudiera existir. Este era el mensaje de la iglesia. Cientos de textos así lo expresaban. Fray Luis de León, por ejemplo, aseguraba que el matrimonio era para Dios la imagen de la unión de Cristo con las almas y la de Cristo con su Iglesia (León 1953:33). Teresa fue más allá, rompió ese cliché pues no solo su alma se veía comprometida en la unión, sino también su cuerpo y así lo explicó:

\begin{abstract}
Víale en las manos un dardo de oro largo, y al fin de el hierro me parecía tener un poco de fuego, éste me parecía meter por el corazón algunas veces y que me llegava a las entrañas. Al sacarle me parecía las llevaba consigo, y me dejaba toda abrasada en amor grande de Dios. Era tan grande el dolor que me hacía dar aquellos quejidos, y tan excesiva la suavidad que me pone este grandísimo dolor, que no hay desear que se quite, ni se contenta el alma con menos que Dios. No es dolor corporal, sino espiritual, aunque no deja de participar el cuerpo algo, y aún harto. (Santa Teresa 2015: 158)
\end{abstract}

Ser monja implicaba sometimiento a los dictados de las normas establecidas, pero para Teresa fue solo una palabra. Al declarar que se sujetaba a la iglesia, a los prelados, a sus superiores... enarboló la bandera de la libertad; la que le otorgaba sentirse una con Cristo, el Verbo. Así su palabra fluirá libre, viva, invadiendo un espacio negado, vigilado, dirigido (Santa Teresa 2015: 69). 
Igualmente, su auto-humillación (Santa Teresa 2015: 115), la repetición de su ruindad, de su declararse "mujercilla que nada valía", no hará sino provocar el efecto contrario a la natural repulsa hacia un ser indigno: admiración, respeto, reconocimiento de valor. Sus consejos adquirirán mayor rotundidad cuando ella les reste mérito: "Mire que para muchas cosas conviene que quizás no las entiende vuestra señoría allá como yo que estoy acá, y que aunque las mujeres no somos buenas para consejo, que alguna vez acertamos" (Santa Teresa 2015: 968).

Será capaz de saltar las normas y no confesar aquello que estime inconveniente (Santa Teresa 2015: 169), o de sortear la obediencia debida a las autoridades de su Orden y buscar directamente apoyo en Roma bajo pretexto de mandato divino (Santa Teresa 2015: 183). Estimará necesario comenzar sus fundaciones sin demora y sin "escuchar pareceres" y lo preparará todo en sigilo hasta tenerlo resuelto (Santa Teresa 2015: 184).

Cuando le recordaron que las monjas debían permanecer enclaustradas según las disposiciones paulinas, ella opondrá que Dios le había dicho: "Diles que no se sigan por solo una parte de la Escritura, que miren otras, y que si podrán por ventura atarme las manos" (Santa Teresa 2015: 601). Más tarde, cuando se le ordenó elegir un monasterio y no salir más, declarará que en lugar de hacerle mal le habían hecho un bien (Santa Teresa 2015: 964).

En suma, recurrir al rol de sumisa y obediente no será más que una argucia, lo mismo que sucederá con el ejercicio del poder. Se denunciaba sin él: "una mujercilla tan sin poder como yo", para otorgárselo a continuación al confesar que hubo de bendecir a un obispo arrodillado a sus pies: “...mire que sentiría cuando viese un tan gran perlado arrodillado delante de esta pobre mujercilla, sin quererse levantar hasta que le echase la bendición en presencia de todas las relisiones y cofradías de Sevilla" (Santa Teresa 2015: 978). Teresa se afirmaba en el poder que le otorgaba Dios, un poder capaz de señorear la tierra (Santa Teresa 2015: 117, 602).

Aparte de ese poder Teresa sentirá recibir también de Dios su autoridad (Santa Teresa 2015: 104) y ello la capacitará para disputar con los letrados (Santa Teresa 2015: 191). Una vez conseguido el beneplácito de la jerarquía masculina utilizará dicha 
autoridad para afirmarse en ella sin considerarse incursa en error (Santa Teresa 2015: 882). Usará de ella para dirigir, disponer, reprender e incluso ordenar formas de actuación, tal como hiciera con Jerónimo Gracián (Santa Teresa 2015: 117, 962). Se sentirá igualmente autorizada para des-autorizar a quien presumiera de una autoridad que para ella era ficticia si no emanaba de Dios (Santa Teresa 2015: 119).

Teresa transgredirá igualmente los límites impuestos a los conocimientos femeninos:

\begin{abstract}
Porque el hablar nace del entender, y las palabras no son sino como imágenes o señales delo que el ánimo concibe en sí mismo; por donde, así como la mujer buena y honesta la naturaleza no la hizo para el estudio de las ciencias, ni para los negocios de dificultades, sino para un solo oficio simple y doméstico, así les limitó el entender, y por consiguiente les tasó las palabas y las razones... (León 1953: 234)
\end{abstract}

Ella era culta y estimaba enormemente el saber (Santa Teresa 2015: 36). Tras sus lecturas juveniles, que según su juicio la habían conducido a planteamientos equivocados (Santa Teresa 2015: 38), se reconocerá siempre amiga de los buenos libros. Su preparación la llevará a percatarse de la ignorancia de muchos clérigos y confesores inconvenientes (Santa Teresa 2015: 117, 629), incapaces de guiar a sus hijas espirituales tal como pondrá de manifiesto en repetidas ocasiones, pues hubo de sufrirlo en sus carnes (Santa Teresa 2015: 82). El amor de Dios la investirá de un conocimientos para el que no necesitará intermediarios, especialmente para su relación con Él (Santa Teresa 2015: 85). Este conocimiento será inmediato. Tendrá un don especial para entender, para saber con el sabor de las formas, de los colores, de los olores, pues tal y como indica Milagros Rivera:

Teresa tenía una relación carnal con la lengua, para ella la palabra no eran cosas mentales lanzadas para intervenir en otras mentes, sino que también eran cosas materiales, plásticas y tangibles, olorosas y vivas, que le ponían delante escenas, relaciones, consecuencias, maravillas, misterios, desastres cuando las pronunciaba, como si al hablar viera ya existir las cosas. (Rivera 2014: 47-49) 
Declarará que la divinidad había hecho posible en su mente disponer de un conocimiento intuitivo, sin estudio, sin esfuerzo por su parte, pues era fruto del espíritu compartido con la sabiduría divina: "Porque el entendimiento está entonces, de verse cerca de la luz, con grandísima claridad, que aun yo, con ser lo que soy, parezco otra... Y es ansí que me ha acaecido.... no solo entender el verso en romance, sino pasar adelante en regalarme de ver lo que el romance quiere decir" (Santa Teresa 2015: 90). De ahí que aunque aparentemente menospreciase su saber, aunque buscase el refrendo masculino (Santa Teresa 2015: 103), consiguió sagazmente mostrar sus experiencias, presentadas como un libro de vida donde cualquiera podía aprender (Santa Teresa 2015: 116-117), especialmente sus hijas a quienes recomendará avanzar sin miedos y sin dar crédito a quienes negaban a las mujeres el camino de la perfección (Santa Teresa 2015: 323, 325, $327,329)$.

Como maestra apropiada de la palabra cometió de nuevo una transgresión enorme, ya que a las mujeres ni se les permitía tener ideas propias, ni interpretar las palabras de reputada autoridad -máxime las divinas- y mucho menos enseñarlas. En el colmo de esa insubordinación llegó a realizar la exégesis del Cantar de los Cantares y contradecir las cultísimas interpretaciones anteriores:

Dirán que soy una necia, que no quiere decir esto, que tiene muchas significaciones, que está claro que no havíamos de decir esta palabra a Dios, que por eso es bien estas cosas no las lean gentes simples. Yo lo confieso que tiene muchos entendimientos; más el alma que está abrasada de amor que la desatina, no quiere ninguno sino decir estas palabras... ¿Que nos espanta? ¿No es de admirar más la obra?... el beso es señal de paz y amistad grande entre dos personas. (Santa Teresa 2015: 427)

En su correspondencia descubriremos a una mujer vital, impetuosa, según su propia declaración: "De mi natural suelo, cuando deseo una cosa, ser impetuosa en desearla" (Santa Teresa 2015: 594), fuerte: "Por grandísimos trabajos que he tenido en esta vida no me acuerdo haverlas dicho, que no soy nada mujer en estas cosas, que tengo recio corazón" (Santa Teresa 2015: 594-595), que se relacionará con su familia, con las prioras 
de los conventos que fundó, con grandes personalidades del momento, que gestionará, administrará, resolverá entuertos, aconsejará... Todo ello con independencia de que, contradictoriamente, pondrá de manifiesto su máxima de no depender de nadie para no perder su libertad. Una libertad que deseará saborear sin cortapisas (Santa Teresa 2015: 1148), sin compromisos que se viera obligada a devolver (Santa Teresa 2015: 893). Una libertad que también obtendrá de Dios (Santa Teresa 2015: 594, 1136) y que expresará por amor (Santa Teresa 2015: 1163), pues la recibió al alcanzar la perfección con independencia de las servidumbres que la obediencia o las situaciones externas le demandaban (Santa Teresa 2015: 690).

Teresa será exceso, pasión, vehemencia. Eso no le restará simpatía (Santa Teresa 2015: 1019), alegría, proximidad y locuacidad (Santa Teresa 2015: 104, 954), que en ocasiones darán lugar a situaciones divertidas y jocosas (Santa Teresa 2015: 1013). Nada la contendrá, ni su vida, ni sus experiencias, porque todo su yo se proyectará al infinito. Ella tendrá la convicción suficiente para saltar por encima de los impedimentos, aunque mujer y físicamente más débil que el resto dadas sus gravísimas y continuas enfermedades. Teresa no será amiga de mortificaciones y así lo manifestará en numerosas ocasiones (Santa Teresa 2015: 78), pero exhibirá su cuerpo transido por dolores insoportables, acercándose con ello al padecimiento de Cristo y a su semejanza liberándose de su corporeidad pecadora, resucitando glorificada. Teresa, mujer y enferma, será no solo aceptada y amada por la divinidad, sino exaltada por ella.

En definitiva, y en contra de todos los planteamientos de la época, Teresa se escapará al control masculino, será especialmente lúcida e inteligente, con una inteligencia que le hará con-ceder, sin ceder realmente en su objetivo: tras-cender, aunque para ello tuvo que saltarse todas las normas de su época con respecto a las mujeres. De hecho, Felipe Sega, el nuncio del papa en España, la definió en 1578 como: "fémina inquieta, andariega, desobediente y contumaz... andando fuera de la clausura contra el orden del concilio tridentino y los prelados. Enseñando como maestra contra lo que san Pablo enseñó, mandando que las mujeres no enseñaran” (Fernández 1991: 345). 
No le importará tampoco afirmar que Cristo estaba entre los pucheros (Santa Teresa 2015: 690), lugar donde habitualmente vivían y convivían las mujeres y donde más de una rebelde predicó la palabra de Dios, entre ellas la alumbrada María de Cazalla (Giordano 1998: 68).

\section{Un tiempo de violencias}

La Edad Moderna fue, como la etapa histórica anterior y como las siguientes, una etapa de violencias ya que esta desafortunada mácula va tomando formas diferentes y no nos ha abandonado todavía. La violencia es percibida en función de las categorías morales y la concepción que las sociedades tienen en torno a la realidad y el valor de la vida. En consecuencia, lo que se consideraba violencia en tiempos de Teresa puede no serlo hoy y viceversa. Por ejemplo, dar tormento para obtener la verdad de las personas acusadas sería, teóricamente, en nuestro siglo XXI, una aberración. Sin embargo, en el XVI era algo normalizado dentro del juego judicial y relacionado con las antiguas pruebas: ordalías, duelos judiciales, juicios de Dios... El reo triunfaba aguantando o fracasaba al confesar (Benassar 1984: 97-98).

Aparte de las violencias sufridas en general por cualquiera, existía una violencia generalizada que afectaba exclusivamente a las mujeres con independencia de su edad, estado y condición social; una violencia estructural que sustentada por la misoginia patriarcal se hallaba en todos los discursos teóricos y conducía y justificaba el ejercicio de una violencia inferida o directa que, a nivel individual padecía una gran mayoría de mujeres, ya fuera de forma física, psicológica, religiosa, económica, sexual, etc.

Teresa recibió dicha violencia estructural como el resto de sus contemporáneas y la asumió (Santa Teresa 2015: 686), al declararse débil físicamente, ruin en sus cualidades morales, necia intelectualmente y sumisa a la autoridad masculina aunque su comportamiento contradijese su palabra. En cuanto a la violencia inferida la recibió de su padre cuando no le autorizó a ingresar en el convento y hubo de escaparse, cuando se la 
obligó a permanecer en la clausura porque al ser mujer y monja no debía seguir realizando fundaciones, etc.

Con ser importantes estas violencias fueron otras las que le causaron mayor estremecimiento y preocupación. Llegaron de la mano de instituciones y personas más o menos próximas a ella: la Inquisición, la orden calzada y hombres y mujeres que quisieron perjudicarla tanto a ella como a su obra.

La Inquisición vigilaba la ortodoxia y el comportamiento cristiano. Sus métodos causaban pavor pues supo desarrollar una pedagogía del miedo provocada, no tanto por la tortura, que aplicaban también los tribunales civiles, como por el entramado de acciones que la rodeaban; especialmente el secreto en el que eran mantenidas las personas detenidas, la pervivencia durante años de la infamia recaída sobre quienes eran condenados y su descendencia y, finalmente, la miseria más absoluta en que se hundían los condenados por las confiscaciones, exilios, etc. (Benassar 1984: 110-124).

La Inquisición espiaba a muchas personas y entre las mujeres a aquellas que se mostraban singulares: beatas, místicas, estigmatizadas, visionarias, etc. Aquellas que llevaban una vida diferente, que se atrevían a adueñarse de la palabra, a convertirse en maestras, a interpretar las escrituras, a otorgarse autoridad, a mostrarse elegidas por la divinidad, etc. También a las que abrazaban planteamientos heterodoxos, ya vinieran de fuera: erasmistas y luteranos, ya procedieran de la propia idiosincrasia peninsular, especialmente del alumbradismo.

Teresa y su obra recordaban peligrosamente a personas y obras ya condenadas, por ello levantó recelos y sospechas durante toda su vida. Su obra literaria fue denunciada y puesta en cuestión numerosas veces (Huerga 1978: 615-616), máxime cuando se utilizó como justificación a prácticas que se juzgaron heréticas, como sucedió en el proceso del doctor Bernardino Carleval, rector de la Universidad de Baeza (Alegre 2013:473). De ahí que quedase a buen recaudo durante mucho tiempo y que fuese rigurosamente revisada por los eclesiásticos más radicales. Cuando finalmente se declaró que no había error en ella, Teresa no pudo eludir su gran satisfacción (Santa Teresa 2015: 1089). 
En cuanto a las prácticas piadosas, si bien no rechazó las fórmulas externas del ritual católico, insistía en el recogimiento y la oración mental a las que llegó, según su propia confesión, a través del Tercer Abecedario de fray Francisco de Osuna (Santa Teresa 2015: 42). Bien por su propio sentir, bien consciente del peligro que la rodeaba si incurría en algún desliz, Teresa se separó de las corrientes condenadas. En el Libro de la Vida se declaró contraria a ciertas actitudes femeninas supersticiosas criticadas por la autoridad eclesiástica, seguramente en referencia a beatas y alumbradas (Santa Teresa 2015: 50) e, igualmente de los luteranos de quienes manifestó sentir pena por haberse apartado de la Iglesia (Santa Teresa 2015: 174).

Obviamente, debió ser vigilada por ser descendiente de conversos y penitenciados. Por otra parte, debió ser preocupante para sus jueces la relación que Teresa mantenía con el demonio -y que salpica toda su obra-, como sucedía con muchas mujeres de su época a las que más que venerar era preciso exorcizar. Para Teresa el demonio era absolutamente real y según sus manifestaciones lo sufrió en sus carnes y en su espíritu con intensa violencia empeñado en apartarla del camino de perfección (Santa Teresa 2015: 38, 40, 161, 165). Tentada y abrumada por el maligno, llegó a contemplar incluso el infierno en una de sus visiones. Su descripción responde a la imagen que de él se tenía en la época (Santa Teresa 2015: 173).

Por otro lado, en la apertura de los sumarios tuvieron mucho que ver las denuncias cursadas contra ella por personas cargadas de prejuicios, envidiosas de su personalidad arrolladora, de su intensa vida interior, o enemistadas por diferentes motivos. Tal ocurrió con la princesa de Éboli, María del Corro y el confesor de esta entre otros. Estas personas vertieron sobre Teresa diferentes acusaciones: mantener un espíritu visionario, seguir falsa doctrina, proclamar la supremacía de la oración mental... Para que nada faltase fue acusada indignamente de mantener una relación condenable con el Padre Gracián, precisamente ella, que tanto había cuidado porque sus hijas no sostuviesen tratos que pudieran dar lugar a murmuraciones ni en el locutorio, ni parte alguna con frailes que no fuesen sus confesores (Santa Teresa 2015: 974). 
Parece ser que Teresa anduvo durante mucho tiempo ignorante de la vigilancia a que fue sometida. Avisada de ello por el padre Gracián no tuvo miedo. Reposaba en Dios y se encontraba segura (Santa Teresa 2015: 1432), aunque no confiase en la justicia de los hombres (Santa Teresa 2015: 974). Y, de todas formas, no dudaba en abrazar cualquier tipo de sufrimiento si ello significaba servir a sus ideales (Santa Teresa 2015: 78), lo que había soñado desde bien pequeña cuando quiso ir a tierra de moros para que la descabezasen (Santa Teresa 2015: 35).

Teresa únicamente temía una cosa: que se anulase su palabra, que se la silenciase (Santa Teresa 2015: 955), que la reforma que había iniciado impulsada por la voz de Dios quedara ahogada en el tiempo, pues se sentía llamada a gritar el rico mundo interior que la penetraba y ella consideraba serviría provechosamente a muchos (Santa Teresa 2015: 1011).

Teresa recibió violencias del colectivo calzado desde el momento en que decidió emprender la reforma de un Carmelo donde consideró que se habían relajado demasiado las costumbres, que faltaba la pobreza, la humildad, el recogimiento y en ocasiones la decencia. "Los pardos", como ella denominaba a los calzados, entendieron a su vez que era una violencia contra ellos conducirles hacía principios que no deseaban. Reaccionaron enfrentándose a aquella mujer rebelde con todas las armas que pudieron, tanto las monjas como los frailes:

Estava muy malquista en todo mi monasterio, porque quería hacer monesterio más encerrado. Decían que las afrentava, que allí podía también servir a Dios, pues havía otras mijores que yo; que no tenía amor a la casa, que mijor era procurar renta para ellas que para otra parte. Unas decían que me echasen en la carcel; otras, bien pocas, tornaban algo de mí. (Santa Teresa 2015: 178)

Teresa se quejaba de la incomprensión, desaires y persecución que recibieron ella y los suyos a veces con dolor, a veces con fastidio o vergüenza (Santa Teresa 2015: 1196), otras con resignación (Santa Teresa 2015: 1195) y en ocasiones con cierta chanza: 
...hánle informado de manera los del paño (al nuncio) y él dádoles tanto crédito, que no sé en qué ha de parar. De mí le dicen que soy una vagamunda y inquieta, y que los monesterios que he hecho ha sido sin licencia del papa ni del general. Mire vuestra merced qué mayor perdición ni mala cristiandad podía ser... Otras muchas cosas que no son para decir tratan de mí esos benditos... le diga que aunque soy ruin mucho, no tanto que me atreviese a lo que dicen. (Santa Teresa 2015: 11821183)

Sus enemigos jamás perdieron ocasión de perderla y echar al traste su obra. A finales de 1575, en Sevilla, una novicia delató a Teresa y a la comunidad a la Inquisición. El proceso fue largo y a él arrojaron lumbre fray Diego de Cárdenas, provincial calzado y visitador vehemente, un confesor hipocondríaco, escrupuloso e ignorante y dos monjas de pocas luces, Beatriz de la Madre de Dios y Margarita de la Concepción (Santa Teresa 2015: 1206). La priora María de San José fue destituida de su cargo y encarcelada. En su lugar se nombró a una de las acusadoras, Beatriz. El cargo principal fue de "ilusas por el demonio con apariencia de perfección espiritual". Las monjas fueron sometidas a interrogatorio y para obtener su confesión se las amenazó con la excomunión. De este modo, y según el parecer de Teresa, se lograron confesiones indignas y así lo trasladó a Hernando de Pantoja (Santa Teresa 2015: 1200). A dicha carta añadió el Obispo de Osma, Juan de Palafox, una nota en que se refería al modo de forzar falsas confesiones, especialmente si querían obtenerse de "mujeres":

Para hacer un proceso ageno a lo sucedido, aunque sea buena la intención (y más con mujeres) no es menester más que un poquito de enojo en la pregunta; un poquito de deseo de probar lo que se quiere en el que escribe, y otro poquito de miedo en el que atestigua; $y$ con estos tres poquitos sale después una monstruosidad y horrenda calumnia. (Torres 1864: 504)

Cuando todo acabó, Teresa no solo perdonó a las falsarias sino que pidió al resto de hermanas que fueran indulgentes con ellas (Santa Teresa 2015: 1211-1212). Por otra parte, en 1578, un grupo de monjas de la Encarnación la eligieron por priora, otro grupo escogió a Ana de Toledo. El escándalo fue tremendo, de modo que sus partidarias fueron 
tratadas con máxima dureza y excomulgadas y todo ello empañado por un gran escándalo (Santa Teresa 2015: 1130).

Las confabulaciones dieron lugar a numerosos infundios (Santa Teresa 2015: 681, 1182). La tristeza que sintió Teresa no era solo por sí misma, sino por la suerte de la reforma (Santa Teresa 2015: 176), de los monasterios recién fundados y de las personas que los componían. Algunos de sus seguidores, como Fray Juan de la Cruz sufrió cárcel:

\begin{abstract}
Todos nueve meses estuvo en una carcelilla que no cabía bien, con cuan chico es, y en todos ellos no se mudó la túnica, con haver estado a la muerte. Tres días antes de que saliese le dio el suprior una camisa suya y unas disciplinas muy recias, y sin verle nadie. Tengo una envidia grandísima. ¡A usadas que halló nuestro Señor caudal para tal martirio! Y que es bien que se sepa, para que se guarden bien de esta gente. Dios los perdone. (Santa Teresa 2015: 1175)
\end{abstract}

E incluso se temió por su vida en un momento dado: "No creerá hija la pena que tengo porque a mi padre fray Juan de la Cruz lo han desaparecido, y no hallamos rastro ni luz para saber adónde está, porque estos padres calzados andan con gran diligencia en acabar con esta reforma" (Santa Teresa 2015: 1172-1173). Pero por encima de todos los sufrimientos Teresa confió siempre en que la verdad saldría a la luz (Santa Teresa 2015: 1202), y así resultó.

Finalmente, padeció Teresa, como he dicho, violencias por parte de personas que por envidia, por orgullo, rencor, u otros sentimientos mezquinos intentaron hacerle daño. Entre ellas podemos citar a la princesa de Éboli, a determinados miembros del alto clero, como el nuncio de su Santidad Jerónimo Tostado, Fray Alonso de la Fuente, y alguna que otra monja o novicia. La princesa de Éboli no pudo sufrir la rígida norma del monasterio de Pastrana acostumbrada como estaba a los oros y oropeles, al ordeno y mando y a la brillante vida cortesana preñada de halagos y fastos. Despechada la denunció a la Inquisición (González 2015: 17).

Por su parte, los individuos del alto clero no podían entender que una mujer se atribuyera tantísimas libertades, menos siendo monja, en cuyo caso había de estar más 
obediente y sujeta a la autoridad de los representantes de la Iglesia y a sus mandatos. Así, por ejemplo, el portugués Jerónimo Tostado nombrado vicario general de la Orden del Carmen por el Capítulo General reunido en Piacenza (Italia), el 21 de mayo de 1575, constituyó un verdadero padecimiento para Teresa pues le prohibió seguir haciendo fundaciones y le ordenó se recluyera en un convento (Acedo 1982: 86). Se quejaba de él en sus cartas por no entenderla y por causar a la nueva Orden tanto perjuicio (Santa Teresa 2015: 1132).

Otro agravio le llegó de una viuda llamada María del Corro, que pretendió ser monja en el monasterio sevillano (Torres 1864: 502-503). Como la de Éboli, no encajó en él y terminó por enfrentarse a la fundadora, a pesar de la gran paciencia que derrochó con ella, autorizándole incluso que tuviera un confesor distinto al de las demás monjas. Tuvo que expulsarla. Ella en venganza denunció a Teresa y sus descalzas a la Inquisición, con ayuda de su confesor, de quién se desconoce el nombre (Pacho 2001: 963-964), y de Isabel de San Jerónimo, quien al parecer no era demasiado inteligente (Santa Teresa 2015: 1025). A resultas del proceso, en febrero de 1576, se presentaron los inquisidores a las puertas del convento para realizar los interrogatorios, lo que se estimó más prudente y menos escandaloso que sacar a las monjas y llevarlas a las cárceles secretas. Finalmente el asunto se sobreseyó tras duras pruebas y quebrantos para ellas y para Teresa.

\section{Conclusiones}

Teresa de Cepeda y Ahumada, Teresa de Jesús o Teresa de Ávila forma parte de un grupo de mujeres fuera de lo común y rompedoras que abismándose en su creencia en el ser supremo buscaban su realización personal, su gloria, su identidad, la libertad que la desasía del dominio de quienes la coartaban...

Ella descubrió hurgando en su interior una verdad que dio razón a su existencia. No lo guardó para sí, sino que la compartió generosamente en la idea de que no solo era importante sentir sino transmitir. Se esforzó en ello, en hacerlo bien, en que se la 
entendiera, en que se siguieran sus pasos puesto que no penaba que hubiera nada más allá de su singular experiencia amorosa.

Voluntariosa hasta decir basta, inteligente para manipular situaciones e ideologías y no parecer culpable, incontenible en sus propios moldes y en los externos, no fue como Cristina de Pizán que se lamentaba por la ignominia secular que sufrían las mujeres. Teresa fue más ladina, aceptó su posición genérica y la subvirtió para hacer lo que le vino en gana. Que había que ser sumisa, la que más; que había que respetar las reglas, la que más. Pero todo esto era solo apariencia porque en el fondo, apoyada como Hildegardade Bingen en el principio que el patriarcado mejor entendía y respetaba: la divinidad, consiguió sus objetivos: salir, entrar, dirigirse con autoridad a los grandes personajes de su época, convertirse en intérprete de lo divino, ejercer el magisterio espiritual, etc.

Teresa formó parte de esa España del siglo de Oro tan grande en legados y en miserias. Se dijo de ella que estaba loca, endemoniada, poseída... que era una visionaria, una excéntrica, una inconformista, una casquivana, una hereje, una alumbrada.... Después se la ha tildado de esquizofrénica, paranoica, neurótica, víctima de depresiones continuadas o atacada por la epilepsia... Todo ello necesario para poder entender una actitud, una vida, un ideal y un pensamiento que tanto para sus contemporáneos como para muchos de nosotros resulta incomprensible. Su nombre y su figura no ha dejado nunca indiferente en su tiempo y en el presente.

\section{Referencias bibliográficas}

Alegre Carvajal, Esther. 2013. "El encuentro y la ruptura entre Teresa de Jesús y la Princesa de Éboli: ¿Una cuestión de enfrentamiento personal o un asunto de estrategia política?". eHumanista, 24: 466-478. http://www.ehumanista.ucsb.edu/volumes/volume_24/Regular/ehum24.alegre.pdf. [2.10.2015].

Andrés Robres, Fernando. 2004. "La peregrinación de Anastasio de Fray Jerónimo Gracián”. Poética y cultura en la época Moderna (cambios dinásticos, 
milenarismos, mesianismos y utopías). Eds. Alfredo Alvar, Jaime Contreras y José Ignacio Ruiz. Alcalá de Henares: Universidad de Alcalá. 645-662.

Benassar, Bartolomé. 1984. La inquisición española: poder político y control social. Barcelona: Crítica.

Bernabé Ubieta, Carmen. 2007. "María Magdalena: la autoridad de la testigo enviada". Mujeres con autoridad en el cristianismo antiguo. Eds. Carmen Bernabé Ubieta. Navarra: Editorial Verbo Divino. 19-47.

Cohen, Victoria. 2006. "Con él a solas. Las cartas de Santa Teresa de Jesús a Jerónimo Gracián”. Anclajes, 10: 73-94. https://dialnet.unirioja.es/servlet/articulo?codigo=4794345. [24.09.2015].

Fernández Collado, Ángel. 1991. Gregorio XIII y Felipe II en la nunciatura de Felipe Sega (1577-1581). Aspectos político, jurisdiccional y de reforma. Toledo: Estudio Teológico de San Ildefonso.

Fray Luis de León. 1953. La perfecta casada. Barcelona: Ediciones Hymsa.

Giordano, María Laura. 1998. María de Cazalla. Madrid: Ediciones del Orto.

González Álvarez, Agustina. s/f. “Teresa de Jesús y la Inquisición”. 1-23. http://www.stjteresianas.org/1\%20MAESTROS_Teresa/Escritos/Teresa\%20Inqui sicion.pdf. [10-09-2015].

Huerga, Álvaro. 1978. Historia de los alumbrados. Madrid: Fundación Universitaria Española.

Javierre, José María. 1982. "La sangre judía de Santa Teresa". Boletín de la Real Academia Sevillana de Buenas Letras. Minervae Baeticae, 10: 53-64.

Lisón Tolosana, Carmelo. 1990. Demonios y exorcismos en los siglos de oro. La España mental, 1. Madrid: Akal.

Pacho, Alberto. 2001. "Inquisición”. Diccionario de Santa Teresa de Jesús. Burgos: Monte Carmelo. 960-966.

Pedregal, Amparo. 1998. "Los cristianos ante la familia: renuncia o afirmación". Arys: Antigüedad, religiones y sociedad, 1: 259-277.

Rivera Garretas, María-Milagros. 2014. Teresa de Jesús. Madrid: Sabina Editorial.

Santa Teresa de Jesús. 2015. Obras Completas de Santa Teresa de Jesús. Eds. Efrén de la Madre de Dios y Otger Steggink. Madrid: Biblioteca de Autores Cristianos.

Steggink, Otto. 1987. Sin amor todo es nada. Madrid: Espiritualidad. 
Torres de Castilla, Alfonso.1864. Historia de las persecuciones políticas y religiosas ocurridas en Europa desde la Edad Media hasta nuestros días. Barcelona: Imprenta y librería de Salvador Manero. 